\title{
Dual (Mixed and Bland) Thrombus in Inferior Vena Cava: A Rare Presentation of Hepatocellular Carcinoma
}

\author{
Anil Arora, Pankaj Tyagi, Praveen Sharma, Naresh Bansal, Vikas Singla, Vinit Shah, \\ Rinkesh Kumar Bansal, Vijendra Kirnake, Kishan S Rawat, Ashish Kumar
}

\begin{abstract}
Budd-Chiari syndrome (BCS) is defined as hepatic venous outflow obstruction at any level from the small hepatic veins to the junction of the inferior vena cava (IVC) and the right atrium. Hepatocellular carcinoma ( $\mathrm{HCC})$ is the complication of chronic liver disease and it usually presents as decompensation of the known chronic liver disease. HCC rarely present as BCS. Here, we present a rare case of $\mathrm{HCC}$ presenting first time with BCS with involvement of hepatic veins and dual thrombus in the IVC.
\end{abstract}

Keywords: Liver cancer, Inferior vena cava thrombosis, BuddChiari syndrome, Tumor thrombus, Hepatocellular carcinoma.

How to cite this article: Arora A, Tyagi $P$, Sharma $P$, Bansal N, Singla V, Shah V, Bansal RK, Kirnake V, Rawat KS, Kumar A. Dual (Mixed and Bland) Thrombus in Inferior Vena Cava: A Rare Presentation of Hepatocellular Carcinoma. Euroasian J Hepato-Gastroenterol 2013;3(1):81-82.

Source of support: Nil

\section{Conflict of interest: None}

\section{INTRODUCTION}

Budd-Chiari syndrome (BCS) was first described in 1845 with triad of abdominal pain, ascites and hepatomegaly by George Budd ${ }^{1}$ and is defined as hepatic venous outflow obstruction at any level from the small hepatic veins to the junction of the inferior vena cava (IVC) and the right atrium. $^{2}$ Hepatocellular carcinoma (HCC) is the complication of chronic liver disease and it usually presents as decompensation of the known chronic liver disease. HCC rarely present as BCS. ${ }^{3}$ Here, we present a rare case of $\mathrm{HCC}$ presenting first time with BCS with involvement of hepatic veins and dual thrombus in the IVC.

\section{CASE REPORT}

A 62-year-old male a known case of diabetes mellitus type II presented with history of abdominal pain, abdominal distension and fever for 20 days, swelling of both the legs without redness or pain for 15 days, and dyspnea and cough for 10 days. Physical examination was unremarkable except pitting pedal edema. His blood investigation at admission were as follows: $\mathrm{Hb}: 12.9 \mathrm{gm} / \mathrm{dl}$, TLC: 6.8/cumm, platelet: 63 thousand/cumm, INR: 2.1 , serum creatinine: 1.27 , serum bilirubin: $2.3 \mathrm{gm} / \mathrm{dl}$, AST: $42 \mathrm{IU} / \mathrm{ml}$, ALT: $62 \mathrm{IU} / \mathrm{ml}$, SAP: $122 \mathrm{IU} / \mathrm{ml}$, total protein: $6.9 \mathrm{gm} / 1$, serum albumin: $2.7 \mathrm{gm} / 1$. $\mathrm{HBsAg}$ was negative, anti-HCV was positive, $\mathrm{HCV}$ RNA of $367,498 \mathrm{IU} / \mathrm{ml}$ and alpha fetoprotein was $161 \mathrm{mg} / \mathrm{dl}$.
Upper gastrointestinal endoscopy revealed large (grade IV) esophageal varices. Ultrasound of abdomen revealed large intrahepatic mass involving the right and left lobe extending into the hepatic veins and IVC. Triple phase contrastenhanced computed tomography (CT) of abdomen revealed large enhancing mass with arterial enhancement with early washout involving the segment 7 and 8 of the right lobe and segment 3 and $4 \mathrm{a}$ of left lobe. There was tumor extension in the hepatic veins and IVC. In the IVC there were two contiguous different types of thrombi, one of them was tumor thrombus in the intrahepatic and suprahepatic part of IVC and the bland thrombus in the infrahepatic part of IVC (Fig. 1). CECT chest also revealed multiple metastases in the lung. In view of extensive metastatic disease only palliative treatment was offered to the patient. Patient was started on sorafenib and was discharged. The patient is doing well on sorafenib till his last follow-up of 3 months.

\section{DISCUSSION}

HCC is fifth common cancer in the world. ${ }^{4}$ Common organs of metastasis in HCC are lung, brain, adrenal glands. Though microinvasion in hepatic veins are common in large $\mathrm{HCC}$ but BCS is found in less than $1 \%$ of all HCC patients. ${ }^{5}$ There are diverse manifestations of the $\mathrm{HCC}$ with invasion to the main vessels starting from asymptomatic to abdominal pain, anorexia, leg swelling, dyspnea and syncope. HCC usually presents as a decompensation in a known case of cirrhosis; however, HCC can also be the first presentation without previous history of chronic liver disease. HCC presenting

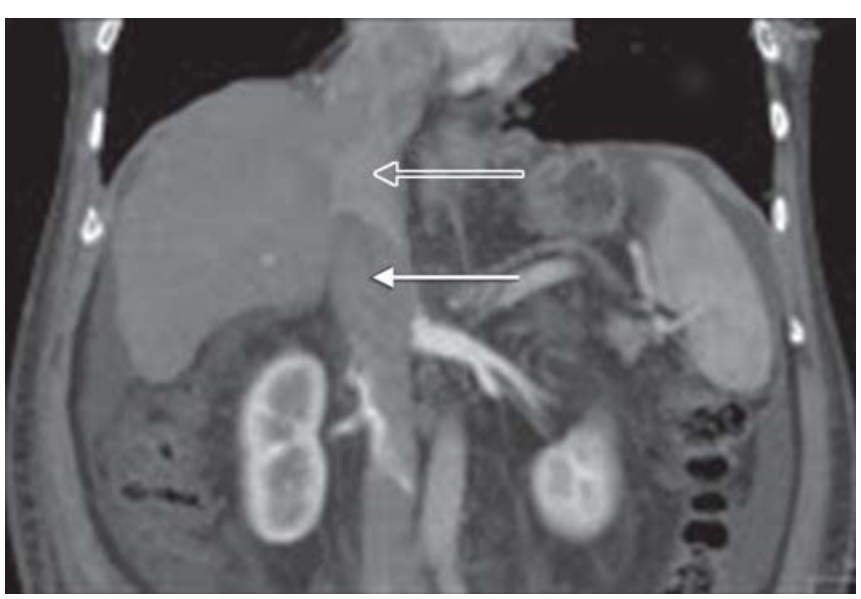

Fig. 1: HCC extensively involving the right lobe of liver with dual thrombus in the IVC, the open arrow shows the tumors invasion whereas the solid arrow denotes the bland thrombus 
with extensive disease with metastasis to distant organ does not merit curative treatment and such patients should be offered palliative treatment.

Our patient presented with many interesting findings that include: First time presentation with HCC, extensive involvement of IVC at first presentation, and IVC with the involvement of dual thrombus, tumor and bland thrombus, in the supra- and intrahepatic IVC.

\section{REFERENCES}

1. Horton JD, San Miguel FL, Membreno F, Wright F, Paima J, Foster P, et al. Budd-Chiari syndrome: Illustrated review of current management. Liver Int 2008;28:455-66.

2. Valla DC. Budd-Chiari syndrome and veno-occlusive disease/ sinusoidal obstruction syndrome. GUT 2008;57:1469-78.

3. Arora A, Tyagi P, Ghuman SS, Sharma P, Kotecha HL, Kumar A. Hepatocellular carcinoma presenting as Budd-Chiari syndrome. J Clin Experiment Hepatol 2012;2(1):91-92.

4. Liu CJ, Kao JH. Hepatitis B virus-related hepatocellular carcinoma: Epidemiology and pathogenic role of viral factors. J Chin Med Assoc 2007;70:141-45.

5. Kao WY, Hung HH, Lu HC, et al. Hepatocellular carcinoma with presentation of Budd-Chiari syndrome. J Chin Med Assoc 2010;73:93-96

\section{ABOUT THE AUTHORS}

\section{Anil Arora}

Chairperson, Department of Gastroenterology and Hepatology Sir Ganga Ram Hospital, New Delhi, India

\section{Pankaj Tyagi}

Consultant, Department of Gastroenterology and Hepatology Sir Ganga Ram Hospital, New Delhi, India

\section{Praveen Sharma}

Consultant, Department of Gastroenterology and Hepatology Sir Ganga Ram Hospital, New Delhi, India

\section{Naresh Bansal}

Consultant, Department of Gastroenterology and Hepatology Sir Ganga Ram Hospital, New Delhi, India

\section{Vikas Singla}

Consultant, Department of Gastroenterology and Hepatology Sir Ganga Ram Hospital, New Delhi, India

\section{Vinit Shah}

Senior Resident, Department of Gastroenterology and Hepatology Sir Ganga Ram Hospital, New Delhi, India

\section{Rinkesh Kumar Bansal}

Senior Resident, Department of Gastroenterology and Hepatology Sir Ganga Ram Hospital, New Delhi, India

\section{Vijendra Kirnake}

Senior Resident, Department of Gastroenterology and Hepatology Sir Ganga Ram Hospital, New Delhi, India

\section{Kishan S Rawat}

Consultant, Department of CT Scan and MRI, Sir Ganga Ram Hospital New Delhi, India

\section{Ashish Kumar (Corresponding Author)}

Consultant, Department of Gastroenterology and Hepatology, Sir Ganga Ram Hospital, New Delhi, India, e-mail: ashishk10@yahoo.com 